\title{
A GEODIVERSIDADE DO SÍTIO GEOMORFOLÓGICO CACHOEIRA DO RIO TAMANDUÁ, CARAMBEÍ, CAMPOS GERAIS DO PARANÁ
}

\author{
Isonel Sandino Meneguzzo ${ }^{1}$ \\ Henrique Simão Pontes ${ }^{2}$ \\ Pedro Crist ${ }^{3}$
}

\section{Resumo}

Este artigo visa descrever a geodiversidade do sítio geomorfológico Cachoeira do Rio Tamanduá (SGCRT), município de Carambeí (Paraná). Os procedimentos metodológicos envolveram pesquisa bibliográfica, análise de carta topográfica e geológica, trabalhos de campo e de laboratório envolvendo a produção de mapa geológico. Na área do sítio foi identificado um conjunto de feições da geodiversidade regional, mostrando potencial para o desenvolvimento de atividades de educação ambiental, contemplação da paisagem, geoturismo, pesquisas científicas e práticas de campo para atividades didáticas. No entanto, é necessária a elaboração de trabalhos de gestão territorial, visando disciplinar os usos do solo existentes no local, sobretudo o turismo, agricultura e silvicultura, adequando com os preceitos da legislação vigente e com as características ambientais do geossítio, a fim de harmonizar as ações e necessidades da sociedade com os princípios da geoconservação.

Palavras chave: Geodiversidade, Geoconservação, Gestão do Território, Carambeí.

\section{THE GEODIVERSITY OF GEOMORFOLOGHICAL SITE OF TAMANDUÁ RIVER WATERFALL, CARAMBEÍ, CAMPOS GERAIS REGION, PARANA STATE}

\begin{abstract}
This article aims to conduct a survey about the geodiversity of the Tamanduá River Waterfall geomorphological site, located in the Carambeí municipality, in Paraná state. The methodological procedures involved bibliographical research, analysis of topographic and geological maps, fieldwork and laboratory studies. In the geossite area many geodiversity features were identified, showing potential for the development of environmental education activities, landscape observation, geotourism, scientific research and field practices for didactic activities. However, it's necessary to realize territorial management in this geosite, aiming to discipline the land uses, such as tourism, agriculture and forestry. The current legislation and the environmental characteristics of the geosite must be respected, seeking to harmonize the actions and society necessity, with the geoconservation principles.
\end{abstract}

Keywords: Geodiversity, Geoconservation, territorial manegement.

\footnotetext{
${ }^{1}$ Professor Adjunto do Departamento de Geociências e docente permanente do Programa de Pós-Graduação em Geografia da Universidade Estadual de Ponta Grossa. Email: meneguzzo@uepg.br

${ }^{2}$ Professor colaborador do Departamento de Geociências da Universidade Estadual de Ponta Grossa. Email: henriquegeografo@gmail.com.

${ }^{3}$ Professor colaborador do Departamento de Geociências da Universidade Estadual de Ponta Grossa. Email: cristpedro1@gmail.com.
} 


\section{LA GEODIVERSIDAD DEL SITIO GEOMORFOLÓGICO CACHOEIRA DO RIO TAMANDUÁ, CIUDAD DE CARAMBEÍ, CAMPOS GERAIS REGIÓN, ESTADO DE PARANÁ}

\section{Resumen}

Este artículo muestra la caracterización de la geodiversidad del sitio geomorfológico Cachoeira do Rio Tamanduá (SGCRT), ciudad de Carambeí (Paraná). Los procedimientos metodológicos incluyeron investigación bibliográfica, análisis de mapas topográficos y geológicos, trabajo de campo y laboratorio. En el área del sitio, se identificó un conjunto de características de geodiversidad regional, que muestran el potencial para el desarrollo de actividades de educación ambiental, observación de paisajes, geoturismo, investigación científica y prácticas de campo para actividades didácticas. Sin embargo, es necesario elaborar trabajos de gestión territorial, con el objetivo de disciplinar los usos del suelo existentes en el lugar, sobre todo turismo, agricultura y silvicultura, adaptándose a los preceptos de la legislación vigente y con las características ambientales del geositio, para armonizar las acciones y necesidades de la sociedad con el principios de geoconservación.

Palabras clave: Geodiversidad, Geoconservación, Gestión Territorial, Carambeí.

\section{INTRODUÇÃO}

A geodiversidade, a diversidade dos elementos abióticos da natureza (rochas, minerais, solo, relevo), é um assunto que vem ganhando destaque nos últimos anos, tanto em nível nacional, como em nível internacional. Visto a relevância da geodiversidade, sendo a base fundamental para o desenvolvimento da vida, estudos a seu respeito são imprescindíveis, assim como sua ampla divulgação tanto na comunidade científica como para a sociedade em geral.

Pesquisas publicadas nos últimos anos (LICCARDO et al., 2008; GUIMARÃES, MELO e MOCHIUTTI, 2009; MOREIRA, 2011; MELO et al., 2011; PONTES e MASSUQUETO, 2012; GUIMARÃES et al., 2013; MASSUQUETO, 2013 e MENEGUZZO, 2015.) vem demonstrando a relevância das feições geológico-geomorfológicas, seja para fins científicos, didáticos, educacionais ou mesmo para o desenvolvimento do geoturismo na região dos Campos Gerais do Paraná e seu entorno imediato.

Diante deste contexto, o principal objetivo deste artigo é o de descrever a geodiversidade do sítio geomorfológico Cachoeira do Rio Tamanduá (SGCRT), localizado no município de Carambeí, estado do Paraná, com vistas a subsidiar possíveis medidas conservacionistas. Dessa forma, este trabalho visa contribuir com conhecimentos envolvendo a geomorfologia e a geologia do local, para que futuras ações na área objeto de estudo sejam realizadas com a finalidade de manejo adequado deste relevante sítio geológico-geomorfológico. 


\section{ÁREA DE ESTUDO}

O SGCRT (Figura 1), situa-se no município de Carambeí, nas coordenadas UTM 578.633 E e 7.247.502 S (Zona 22 J) na região conhecida como Campos Gerais do Paraná.

Situada no Bioma Mata Atlântica, essa região constitui-se numa zona fitogeográfica de predomínio de campos, com a ocorrência de cerrados e matas ciliares ao longo dos rios e arroios e de capões isolados com a existência do pinheiro de Araucária (MAACK, 1950), com extensão original aproximada de $19.060 \mathrm{~km}^{2}$ (MAACK, 2012).

Abrange uma área desde o município de Rio Negro, no limite com Santa Catarina, ao sul, até Sengés, no limite com São Paulo, ao norte (MELO e MENEGUZZO, 2001). A região dos Campos Gerais do Paraná possui um patrimônio geológico e geomorfológico ímpar no contexto do estado do Paraná. Destacam-se formas como relevos ruiniformes, canyons, furnas, cavernas, rios fluindo sobre leito rochoso e em ambientes subterrâneos e escarpamentos entalhados, majoritariamente, em rochas areníticas da Formação Furnas.

Na área do SGCRT, existem remanescentes de vegetação de campos (Estepe GramíneoLenhosa) associados a matas ciliares (Floresta Ombrófila Mista), com significativas intervenções antrópicas que ocorrem nas margens do rio Tamanduá, principalmente devido à contaminação biológica com espécies exóticas, representadas por pinus.

Macrogeomorfologicamente, o SGCRT, encontra-se sobre a unidade morfoestrutural do Segundo Planalto Paranaense. Essa unidade situa-se na borda leste da Bacia Sedimentar do Paraná e caracteriza-se como um relevo levemente ondulado. É constituída principalmente por sedimentos Paleozoicos com idades que variam entre os períodos Ordoviciano ao Permiano (MAACK, 2012).

A estrutura arqueada na borda leste da Bacia Sedimentar do Paraná tem sua origem ligada aos movimentos tectônicos ocorridos principalmente durante a era Mesozoica, mas ativos desde o Proterozoico. Esse tectonismo está relacionado com a separação dos continentes Sul-Americano e Africano, que fraturou a crosta na região, contribuindo para a formação de diversos canyons e falhas de direção NW-SE, por vezes associados com diques de Diabásio (ZALÁN et al., 1990 e MELO, GUIMARÃES e MELEK, 2002). Strugale (2003) afirma que o enxame de diques originados pelo Arco de Ponta Grossa é um dos maiores em termos de quantidade em todo o planeta.

O clima vigente na área de estudo é do tipo $C f b$ do Sistema Internacional de Classificação de Climas de Köppen e Geiger. Apresenta-se como quente-temperado e sempre 
úmido. A média térmica do mês mais quente é inferior a $22^{\circ} \mathrm{C}$, onze meses do ano com temperaturas médias superiores a $10^{\circ} \mathrm{C}$ (MAACK, 2012).

Figura 1. Localização, hidrografia e aspectos geológicos do SGCRT no estado do Paraná.
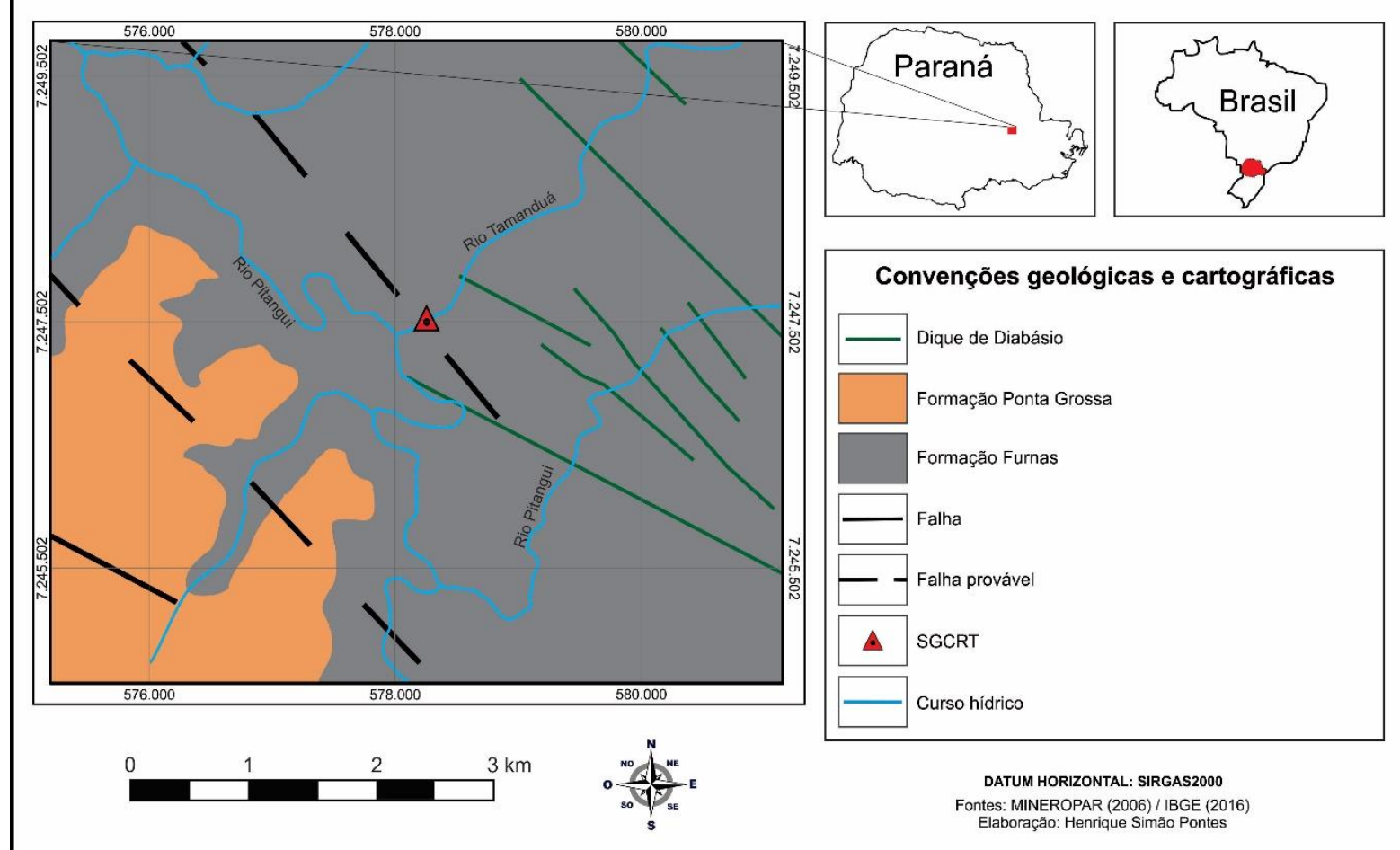

DATUM HORIZONTAL: SIRGAS2000 Fontes: MINEROPAR (2006)/ IBGE (2016)

Em relação ao aspecto hidrográfico o SGCRT situa-se na bacia do rio Tamanduá, afluente da margem direita do rio Pitangui. Ambos os cursos fluviais, na área de estudo, possuem vales assimétricos onde ocorrem afloramentos do Arenito Furnas.

A Formação Furnas, com idade compreendida entre os períodos Siluriano e Devoniano, aflora na região do Segundo Planalto Paranaense, no segmento leste da Bacia Sedimentar do Paraná. A formação é constituída predominantemente por arenitos quartzosos, de granulação média a grossa, com cimentação caulinítica predominante. Apresenta disposição em camadas tabulares, com estratificação sub-horizontal paralela, cruzada e acanalada, com intercalações de estratos de areia fina, sílticos e argilosos (ASSINE, 1999).

A altitude máxima na área do SGCRT é de 912 metros, nos divisores de drenagem do rio São João, na porção leste do geossítio. A altitude mais baixa foi verificada no leito do rio Tamanduá, com 820 metros (DSG, 1958). O acesso à região do SGCRT pode ser realizado pela rodovia PR- 151. Partindo de Ponta Grossa, sentido município de Castro, nas proximidades da área urbana de Carambeí, no km 310 ao adentrar na Avenida dos Pioneiros segue-se por 17 
quilômetros até a localidade de São João. O acesso ao local ocorre por uma entrada à direita da estrada principal, cerca de 50 metros após uma ponte de concreto sobre o rio Tamanduá.

\section{MATERIAL E MÉTODOS}

Diante do objetivo inicialmente proposto, foram realizados os seguintes procedimentos metodológicos:

1) Revisão bibliográfica: O primeiro procedimento para a realização da pesquisa deu-se através do levantamento da bibliografia preexistente referente à área de estudo em seus aspectos gerais, tais como geologia, hidrografia, geomorfologia, vegetação, bem como o histórico e os conceitos envolvendo a geodiversidade.

2) $\mathrm{Na}$ segunda fase foram levantados dados mais específicos relativos às feições geológicas e geomorfológicas de interesse geoturístico adotando os seguintes procedimentos metodológicos:

a) Análise de carta topográfica: Foi consultada e analisada a carta topográfica intitulada "Castro" publicada pela Diretoria de Serviço Geográfico (1958). Por meio dessa análise foram verificadas as cotas altimétricas da área de estudo e o contexto hidrogeográfico do SGCRT.

b) Trabalhos de campo: Foram realizados dois trabalhos de campo no mês de novembro de 2015, com o intuito de identificar os elementos da geodiversidade presentes no SGCRT, através de anotações em cadernetas e registros fotográficos. O inventário da geodiversidade baseou-se nas propostas de baseando-se nos trabalhos de Dias (2003), Gray (2004) e Pontes et al. (2018). Para cada feição identificada foi realizada a descrição de aspectos gerais. Para o mapeamento da gruta foi adotado o método proposto pela Union Internationale de Spéléologie, UIS do ano de 2012, conforme descrito por Häuselmann (2012), com a técnica da poligonal aberta e base fixa. Os equipamentos utilizados para o mapeamento espeleológico foram: uma trena a laser Leica modelo DistoA6, bússola de visada Brunton com clinômetro acoplado, modelo Sight/Clino Master (para meidas de direção e inclinação da cavidade e de estruturas tectônicas) e caderneta. Os dados do mapeamento espeleológico foram tratados em sistema CAD (Desenho assistido por computador).

3) A última etapa consistiu em elaboração de mapa de localização, hidrografia e aspectos geológicos, mapa espeleológico e descrição das feições do geossítio. 


\section{GEODIVERSIDADE: ASPECTOS HISTÓRICOS E CONCEITUAIS}

A partir de 1992, com a realização da Conferência das Nações Unidas para o Meio Ambiente e Desenvolvimento (Rio - 92) emanaram documentos e acordos internacionais focados na proteção ambiental e no desenvolvimento sustentável, porém, a maioria destes possui um viés que direciona para a proteção da biodiversidade (PEREIRA, BRILHA e MARTINEZ, 2008).

O termo geodiversidade é relativamente novo. Surgiu no ano de 1993 em uma conferência realizada no Reino Unido sobre Conservação Geológica e Paisagística (GRAY, 2004). Assim como no contexto internacional, no Brasil os primeiros trabalhos desenvolvidos abordando a geodiversidade e a necessidade de sua conservação também ocorreram a partir da década de 1990 (LOPES; e ARAÚJO, 2011).

No transcorrer de sua breve história, houve várias tentativas de definir geodiversidade conceitualmente. Alguns autores a definiram de maneira bem restrita, na qual ela incluiria somente os aspectos abióticos do ambiente. Já outras definições foram mais abrangentes considerando também os seres vivos (BRILHA, 2005). Entretanto, entende-se que há uma relação direta da geodiversidade com os seres vivos, em uma situação de dependência direta da biota com os elementos abióticos. Assim, a geodiversidade fornece o suporte para a existência e desenvolvimento da vida.

Brilha (2005, p. 17) se baseia no conceito adotado pela Royal Society For Nature Conservation do Reino Unido segundo o qual consiste na variedade de ambientes geológicos, fenômenos e processos ativos que dão origem a paisagens, rochas, minerais, fósseis, solos e outros depósitos superficiais que são o suporte para a vida na Terra.

O conceito da Royal Society For Nature Conservation refere-se especificamente sobre os aspectos abióticos, não havendo especificamente menções aos seres vivos, a não ser a relação de dependência da vida com o suporte físico (BRILHA, 2005).

A ideia de conservação da geodiversidade, sobretudo quantificada e classificada pelos valores apresentados na definição anterior é bem recente. A preocupação com a conservação ambiental é um tema presente na pauta de debates há várias décadas, como aponta Viola (1995). Entretanto, até meados da primeira década do século XXI eram priorizados os elementos bióticos da natureza (biodiversidade). Mesmo que em um ritmo baixo, atualmente tem crescido a consciência de que é preciso proteger a biodiversidade, mas também todo o suporte que lhe propicia condições de existência. Em outras palavras, é preciso proteger e conservar também a 
geodiversidade. O Brasil possui uma legislação ambiental ampla, contudo muito focada na conservação da biodiversidade. Se por um lado a consciência ambiental tem avançado nos últimos anos, a fiscalização e execução da lei não, o que reflete em problemas diversos e um alto risco para a conservação da geodiversidade.

Com a finalidade de conservar a geodiversidade ou em outro termo, promover a geoconservação, algumas estratégias foram e têm sido utilizadas principalmente por aqueles que possuem apreço pela temática e reconhecem a importância da conservação do meio abiótico. Entre essas estratégias se destaca a consideração dos aspectos geológicos e geomorfológicos como patrimônio. Em consonância com Brilha (2005, p. 52), o patrimônio geológico é definido "pelo conjunto dos geossítios inventariados e caracterizados numa dada área ou região." Para o autor o patrimônio geológico é representado pelos elementos ainda na natureza, in situ. Essa é uma ideia que vem sendo reformulada nos últimos anos, e hoje também se considera como patrimônio geológico e geomorfológico peças expostas em museus ou fora do ambiente natural, denominados de elementos da geodiversidade ex situ (BRILHA, 2016). Entende-se que patrimônio geológico é equivalente à geopatrimônio, não demandando diferenciações conceituais na utilização destas terminalogias.

Outra estratégia notória visando a geoconservação consiste na atribuição de valores para a geodiversidade. Embasado em proposições de outros autores e acrescentando o valor funcional, Gray (2004) e Gray, Gordon e Brown (2013) estabelecem os sete principais serviços (valores) atribuídos à geodiversidade: valor cultural, valor econômico, valor intrínseco, valor estético, valor funcional e valor científico e educacional. Ressalta-se que essa valoração é de suma importância, considerando uma visão holística a que tanto se almeja alcançar em estudos de caráter ambiental.

Seguindo essa linha de raciocínio, Guimarães et al., (2009) argumentam que a percepção holística sobre o que é natureza, exige que a geodiversidade e a biodiversidade devam ser vistas de forma indissociável. Dessa maneira, a visão não dicotômica poderia conduzir a uma conservação da natureza envolvendo aspectos bióticos e abióticos.

Ao longo de sua história a humanidade teve relação inerente com a geodiversidade. $\mathrm{Na}$ pré-história determinados sítios geológicos (lapas, grutas) eram utilizados como abrigo, outros elementos da geodiversidade também serviram como estratégia de defesa como aponta Brilha (2005) ao mostrar como exemplo, os antigos castelos que eram construídos em locais mais elevados, o que proporcionava uma visão ampla e privilegiada da paisagem. 
A geodiversidade sempre foi importante para a humanidade no que tange a disponibilidade de recursos (matéria-prima). Cabe citar também a água como um dos elementos mais relevantes da geodiversidade e indispensável à vida humana e de todos os seres vivos (BRILHA, 2005). Hodiernamente, a geodiversidade permeia todo o cotidiano, abrangendo desde o material utilizado na construção civil até os produtos fármacos e cosméticos amplamente consumidos pela sociedade (BRILHA, 2005; CORRÊA; LARA, 2014).

\section{RESULTADOS E DISCUSSÃO}

No SGCRT pôde-se constatar a existência de diversas feições geológicas e geomorfológicas (Figura 2), descritas a seguir:

\section{Lapas}

As lapas são reentrâncias que ocorrem em paredes rochosas, constituindo abrigos naturais (MELO, 2006). De acordo com Melo, Guimarães e Melek (2002) sua origem está associada à erosão mecânica. As estruturas sedimentares favorecem a remoção irregular de fragmentos da rocha, seja pelo peso ou, próximo de cursos fluviais, devido à erosão fluvial (MELO, 2006). Geralmente essas lapas constituem abrigos e estão condicionados a estratos com diferentes granulações do arenito. É comum a ocorrência de camadas compostas por areia fina e laminações síltico/argilosas no teto das lapas, apresentando marcante estratificação planoparalela, características que facilitam o processo de desplacamento e formação das lapas.

\section{Marmitas}

De acordo com Christofoletti (1980) as marmitas são originadas devido ao processo de evorsão, um tipo específico de erosão fluvial. O movimento turbilhonar da água com sedimentos, atuando sobre o leito rochoso em pontos onde os planos de diaclasamento se entrecortam, produz essas depressões com formato visto em planta, geralmente circulares (PENTEADO, 1983). As marmitas podem apresentar poucos centímetros de circunferência e profundidade, como também atingir mais de 3 metros de largura e desenvolvimento descendente, como os exemplos encontrados no Córrego Lajeado do Sobrado (Palmeira) e no Arroio Cambiju (Ponta Grossa).

$\mathrm{Na}$ área do SGCRT foram identificadas marmitas no leito do rio Tamanduá a montante da cachoeira do rio homônimo, uma com aproximadamente 1,60 metro de profundidade e 0,70 
MENEGUZZO, Isonel Sandino

SOCIEDADE E

TUERRITÓRIO
PONTES, Henrique Simã

CRIST, Pedro

centímetros de raio e a outra com 50 centímetros de raio e 85 centímetros de profundidade. Outra marmita foi identificada no leito fluvial do rio Tamanduá, medindo 4,0 metros de profundidade e 1,05 metros de raio. Essa feição desenvolve-se até um plano de acamamento, permitindo que parte das águas do rio entrem na panela e circulem pelo plano de acamamento até a frente do nickpoint, tratando-se, portanto, de um pequeno sumidouro que permite que as águas fluviais tracem um caminho alternativo em uma porção do rio.

Figura 2. Mosaico: a) Caneluras ; b) Marmitas; c) Cachoeira do rio Tamanduá; d) Marmita em leito fluvial; e) Dutos; f) Lapa; g) Bacia de dissolução poligonal.

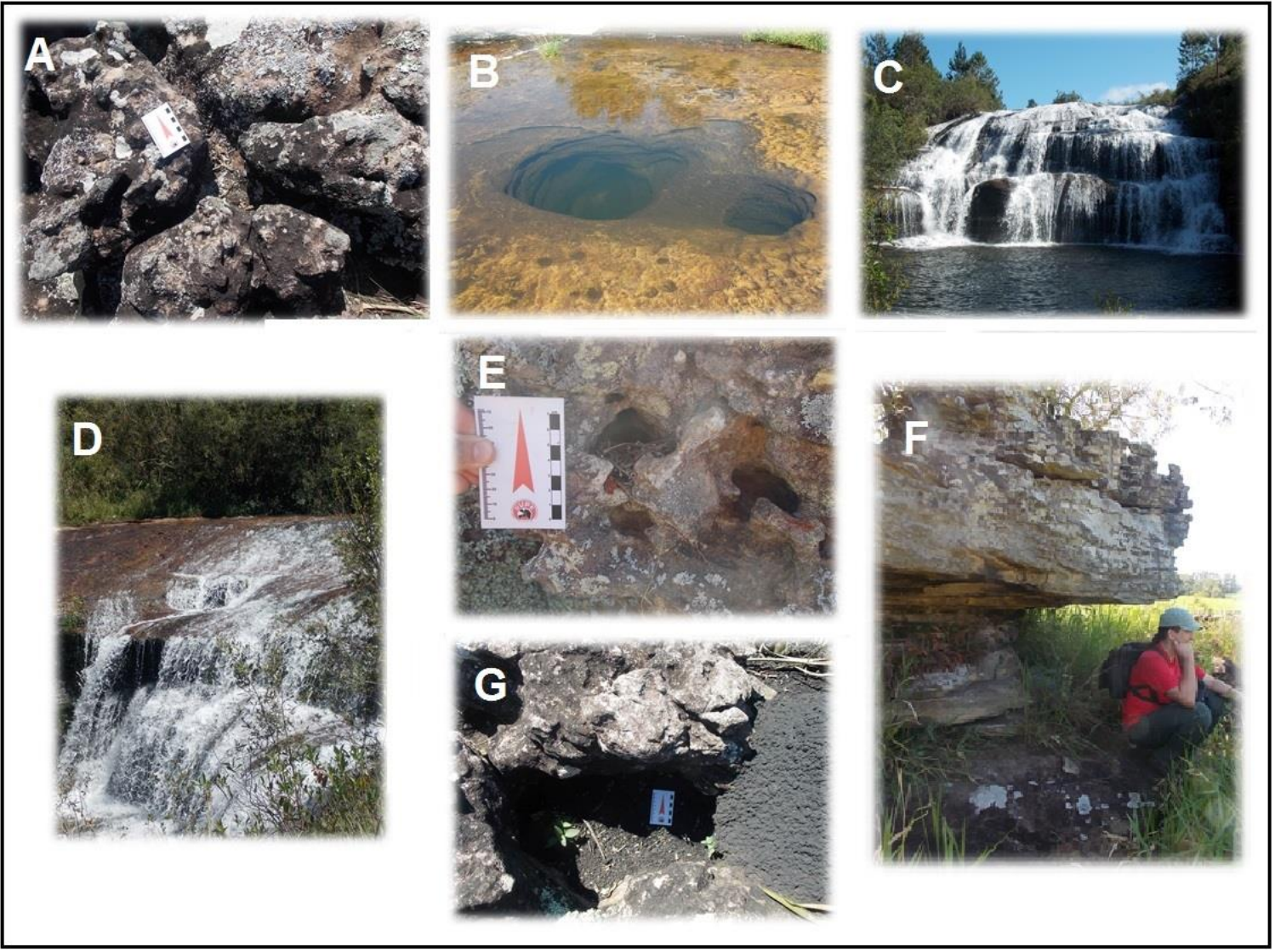

Fonte: Autor (2017)

Organização: CHAICOUSKI (2017)

\section{Cachoeiras}

A origem dessas feições na área de estudo está relacionada principalmente a existência de uma falha provável que intercepta o Rio Tamanduá e pequenos diques de diabásio, conforme dados da Mineropar (2005). Essas estruturas geológicas fazem parte de um conjunto denominado por Pontes (2014) de Lineamento São Jorge, que tem início na área da Escarpa Devoniana, porção denominada de Serra de Itaiacoca (Ponta Grossa) e se estende adiante da 
área de estudo, orientado para NW. No entanto, as estruturas sedimentares e a diferença textural do Arenito Furnas, também influenciam na formação das cachoeiras, pois tais características da rocha respondem de forma diferenciada em relação à ação erosiva das águas fluviais. Na área de estudo a principal feição identificada é a homônima ao sítio geológico, com um desnível de aproximadamente 12 metros. Vale destacar que a montante existe uma sequência de três quedas de menor proporção, porém todas compõem a Cachoeira do Rio Tamanduá.

\section{Bacias de dissolução}

Feições geomorfológicas, denominadas de bacias de dissolução (WRAY, 1997) ocorrem na área do SGCRT. Essas feições constituem-se em pequenas bacias formadas a partir do acúmulo de água em depressões na rocha. Com frequência aparecem líquens nas bordas dessas feições e a água estagnada torna-se mais ácida, ocorrendo a dissolução do cimento caulinítico. A rocha perde coesão, desagregando os grãos de quartzo das paredes e do interior das bacias. A água acumulada seca em períodos de baixa pluviosidade, sobrando apenas areia no interior dessas feições. Com as chuvas, a ação erosiva mecânica das águas pluviais erode mais a rocha anteriormente intemperizada e os grãos acumulados tendem a ser removidos da depressão através de pequenos canais de escoamento. O ciclo se repete, ampliando a bacia cada vez mais, em profundidade e diâmetro (WRAY, 1997).

Segundo Hardt et al. (2009), Massuqueto (2010), Pontes (2010), Hardt (2011), Melo et al. (2011), Pontes (2014) as bacias de dissolução são consideradas feições cársticas, por que o processo de dissolução é um fator condicionante no processo genético.

No geossítio, as bacias de dissolução apresentam diâmetro de cerca de 30 centímetros, por vezes há coalescência entre as feições, e profundidade de aproximadamente 15 centímetros e com presença de líquens. Vista em planta as bacias possuem formato circular, oval e oblonga.

\section{Alvéolos}

Os alvéolos são reentrâncias côncavas, geralmente com tamanho decimétrico, que ocorrem na superfície rochosa (MELO, 2006). Pontes (2014) salienta que essas feições ocorrem nas paredes e tetos, porém não podem ser confundidas com cúpulas de dissolução (descritas mais adiante).

$\mathrm{Na}$ área de estudo estas feições apresentam poucos centímetros e ocorrem em paredes rochosas e no teto das lapas. Melo (2006) aponta que a origem dessas feições está associada à 
combinação da dissolução do cimento dos arenitos com erosão mecânica. Além disso, pôde-se observar na área de estudo a presença de umidade, o que possivelmente contribui para a evolução dessas formas.

Pontes (2014), apresenta outra interpretação genética para os alvéolos, salientando que podem se tratar de núcleos de dissolução iniciados em ambiente freático e aumentados em ambiente epifreático. Essas feições seriam o estágio inicial para a formação dos dutos de dissolução, que se formariam a partir da coalescência de vários núcleos de dissolução. $\mathrm{O}$ autor salienta que a ocorrência de alvéolos em locais fora do alcance de águas meteóricas (como os que ocorrem na área de estudo no teto de lapas), evidencia que tais feições não são formadas apenas por ação erosiva superficial, mas sim em ambientes subterrâneos, com baixa energia, onde o processo químico é mais operante.

\section{Relevos ruiniformes}

Melo (2006, p.81), comenta que "as rochas desfeitas por processos erosivos, que acabam por assumir aspecto de ruínas, dão origem aos chamados relevos ruiniformes. O mesmo autor ainda afirma que a origem dessa feição está atrelada a ação da erosão química promovida pelas águas pluviais e da erosão mecânica. O relevo ruiniforme geralmente é composto por um conjunto de feições, como pináculos, torres, lapiás e caneluras, estas últimas também presentes na área de estudo.

A presença de líquens é relativamente comum nessas formas de relevo, inclusive no SGCRT. Assim, a ação do intemperismo químico-biológico por meio da liberação de substâncias também contribui para a esculturação da rocha. Estruturas sedimentares (planos de estratificação e de acamamento), fraturas e fissuras, e granulação da rocha também são fatores que contribuem para a formação do relevo ruiniforme.

\section{Caneluras}

Essas feições são formadas principalmente pela erosão mecânica das águas pluviais. A dissolução também pode ocorrer, mas em menor escala. As caneluras são caracterizadas por sulcos que cortam a superfície rochosa. Formam-se no mesmo sentido da declividade da encosta e geralmente acompanham diáclases. Este último fator é preponderante para sua gênese, pois as linhas de fraturas são canais preferenciais para o escoamento da água (GUERRA e GUERRA, 2008). 
$\mathrm{Na}$ área de estudo foram identificadas caneluras em arenitos da Formação Furnas, na margem esquerda do rio Tamanduá a jusante e a montante da cachoeira.

\section{Sumidouro e ressurgência}

No SGCRT essa feição é identificada na porção superior de uma das quedas de água que há no local, com desnível na cachoeira de aproximadamente 4 metros.

Sumidouro são pontos onde ocorre a captura de águas superficiais, encaminhando a drenagem para ambiente subterrâneo. Nesses casos, o curso hídrico deixa de ter escoamento superficial e passa para uma drenagem criptorreica, através de uma caverna, duto, fenda ou qualquer outro tipo de cavidade subterrânea. $\mathrm{O}$ ponto onde o rio volta a drenar superficialmente é denominado ressurgência, podendo ser confundido com nascentes (springs), que nesse caso seria classificado como uma surgência.

\section{Gruta}

No local da presente pesquisa há uma gruta, situada na base da Cachoeira do rio Tamanduá, mais precisamente no seu lado direito na perspectiva de visão frontal. Com desenvolvimento linear de 7,5 metros, desnível de 1,8 metros e altura média de 3 metros, a gruta é controlada por uma estrutura de direção $\mathrm{N} 55^{\circ} \mathrm{W}$, relacionada com a falha provável que intercepta o geossítio, de SE à NW (figura 3).

No interior da cavidade subterrânea há uma surgência de água, formando pequeno canal, além de dutos de dissolução e cúpulas de dissolução, conforme descritos nos tópicos a seguir. 


\section{Figura 3 - Mapa espeleológico da Gruta do Tamanduá.}

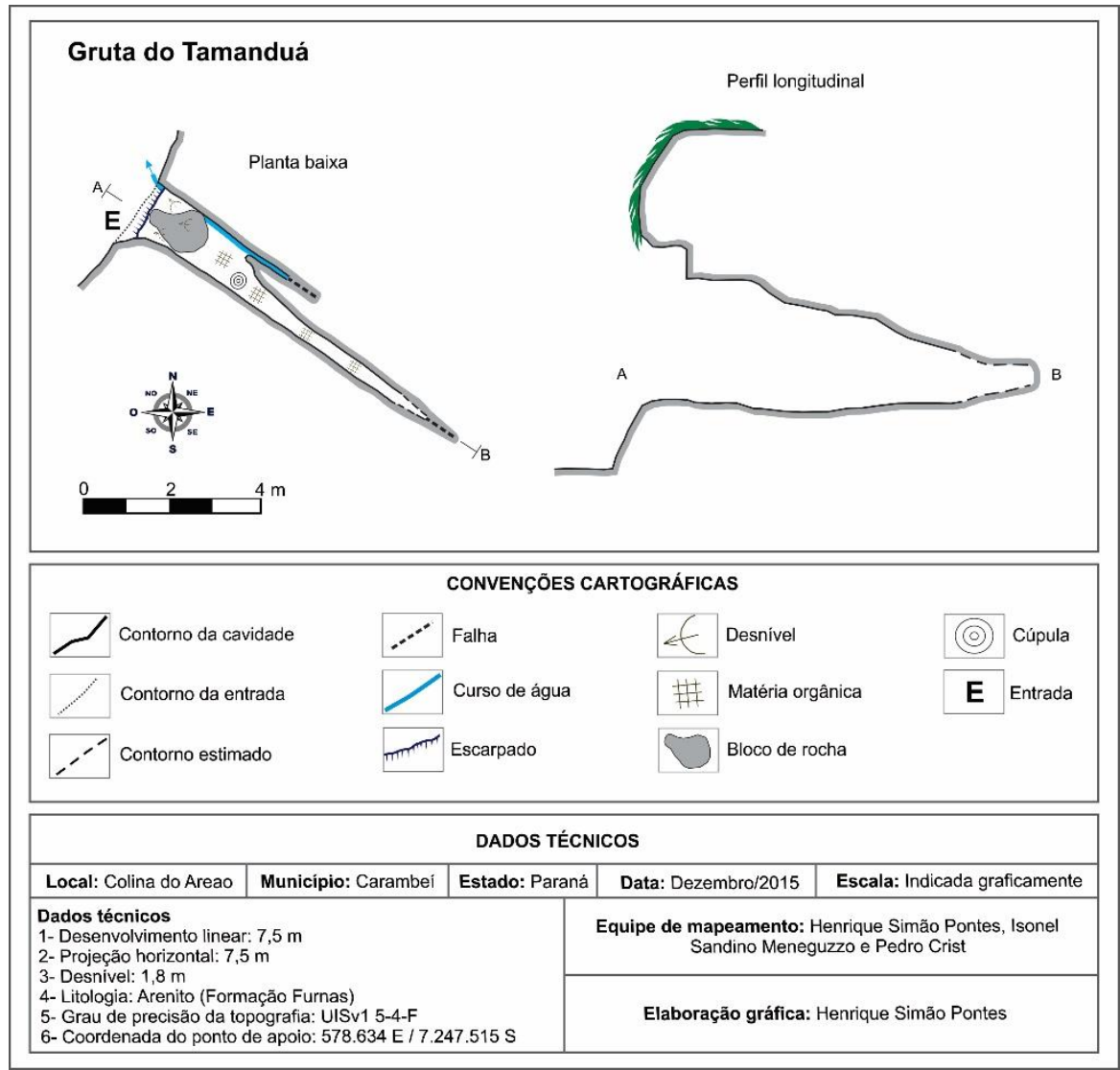

\section{Dutos de dissolução}

$\mathrm{Na}$ área de estudo essas feições ocorrem no interior da Gruta do Tamanduá e em um paredão rochoso, constituído de arenitos, pertencentes a Formação Furnas, próximo à cachoeira, apresentando até 10 centímetros de circunferências. Os dutos de dissolução da Formação Furnas são canais subterrâneos, caracterizados por Massuqueto (2010) e Pontes (2014) como antigos canais de drenagem subterrânea, que podem apresentar estrutura retilínea sem ramificações ou uma rede de dutos hierarquizados, interconectados como uma rede de drenagem.

Essas feições são representadas por cavidades com perfil arredondado, comuns em paredões rochosos, cavernas e sumidouros e seu principal agente morfogênico é a água (MELO et al., 2011).

Wray (2009), ao estudar dutos em rochas areníticas da Austrália, propõe que esses canais são formados em ambientes unicamente epifreáticos. Para Pontes (2014) a formação dos dutos de dissolução, ocorre a partir da coalescência de vários núcleos de dissolução, inicialmente desenvolvidos em ambiente freático, evoluindo para uma zona epifreática. Dessa 
maneira, os dutos de dissolução também são feições chaves para a classificação do relevo da Formação Furnas como cárstico, pois a dissolução é preponderante na formação da feição.

Massuqueto (2010) e Pontes (2014) mostram exemplos na Formação Furnas de casos onde drenagens superficiais são capturadas por sumidouros e passam a escoar através de dutos de dissolução, que podem atingir diâmetros maiores que 3 metros, como é o caso do Sumidouro do Rio Quebra-Perna (Ponta Grossa).

\section{Cúpulas de dissolução}

Caracteriza-se como uma reentrância côncava no teto de uma cavidade subterrânea, ou no caso das rochas da Formação Furnas pode ocorrer no teto de lapas. Apresenta desenvolvimento ascendente e quando evoluídas (nos casos onde atingem desenvolvimento vertical com mais proeminência do que seu diâmetro) podem formar chaminés de equilíbrio. Sua existência não implica na ligação da gruta com o ambiente externo ou com outra gruta (SPOLADORE, 2006).

As cúpulas são feições que evidenciam o processo de dissolução do arenito. Sua formação pode estar relacionada com a ação de águas subterrâneas (em ambiente epifreático) que erodem o teto de cavidades quando na subida de fluxo. Klimchouk (2009) classifica as cúpulas de dissolução como pontos de saídas de fluxo (outlets), e faz parte de um conjunto denominado de suíte morfológica de subida de fluxo (MSRF - morphologic suite of rising flow), feições encontradas em sistemas subterrâneos que apresentam espeleogênese hipogenética. $\mathrm{Na}$ área de estudo foram identificadas cúpulas apenas no interior da gruta, não havendo registro de outras feições que compõem estas suítes morfológicas (canais de teto e de parede - half-tubes e os alimentadores - feeders).

\section{CONSIDERAÇÕES FINAIS}

O recorte espacial do presente estudo é uma das diversas áreas que representam a geodiversidade dos Campos Gerais. Com a identificação dos elementos geológicos e geomorfológicos do SGCRT foi possível atribuir alta relevância ao patrimônio natural em questão. O local tem potencial para o desenvolvimento de atividades de educação ambiental, observação da paisagem, práticas de campo envolvendo alunos de instituições de ensino superior, atividades didáticas no ensino fundamental e médio, geoturismo, bem como pesquisas científicas. 
A geodiversidade do SGCRT é representada por onze feições, (lapas, marmitas, cachoeiras, bacias de dissolução, alvéolos, relevos ruiniformes, caneluras, sumidouro e ressurgência, dutos de dissolução, gruta e cúpulas de dissolução). Algumas dessas feições são produtos do processo de dissolução dos arenitos da Formação Furnas, evidenciando a existência de carstificação nessa unidade geológica.

O presente trabalho constitui uma ferramenta para a gestão sustentável do sítio geológico em análise. No entanto, mais estudos devem ser realizados para um melhor detalhamento da área, envolvendo as feições geológicas e geomorfológicas do SGCRT, seus aspectos genéticos e evolutivos.

É necessária a elaboração de trabalhos de gestão do território, visando disciplinar os usos do solo existentes no local, considerando que a área é majoritariamente utilizada por banhistas em períodos de calor. Faz-se necessário que a legislação vigente e as características ambientais do geossítio sejam respeitadas, buscando-se harmonizar as ações e necessidades da sociedade com os princípios da geoconservação.

\section{REFERÊNCIAS}

ASSINE, M. L. Fácies, icnofósseis, paleocorrentes e sistemas deposicionais da Formação Furnas no flanco sudeste da Bacia do Paraná. Revista Brasileira de Geociências, v. 29, n. 3, p. 357-370, 1999.

BRILHA, J. Patrimônio geológico e geoconservação: a conservação da natureza na sua vertente geológica. Palimage: Braga. 2005.

BRILHA, J. Inventory and Quantitative Assessment of Geosites and Geodiversity Sites: a Review. The European Association for Conservation of the Geological Heritage. Geoheritage. n. 8, p. 119-134, 2016.

CORRÊA, C. B.; LARA, P. T. Aplicação de Materiais Geológicos. In: LICCARDO, A.; GUIMARÃES, G. B. Geodiversidade na Educação. Ponta Grossa: Estúdio Texto, 2014. Cap. 6, p. 67-76.

CPRM. Mapa geodiversidade do Brasil. Escala 1:2.500.000. Legenda expandida. Brasília: CPRM/Serviço Geológico do Brasil, 2006. 68 p.

CHRISTOFOLETTI, A. Geomorfologia. 2. ed. São Paulo: Edgard Blücher, 1980. 
DIAS, M. S. 2003. Ficha de caracterização de cavidades. Anais do XXVII Congresso Brasileiro de Espeleologia, Januária MG, p. 151-160.

DSG - Diretoria do Serviço Geográfico. Castro. Rio de Janeiro, 1958. 1 mapa: color.; 50 x 55 cm. Escala 1:50.000.

GUERRA, A. J. T.; GUERRA, A. T. Novo dicionário geológico-geomorfológico. 6. ed. Rio de Janeiro: Bertrand, 2008.

GRAY, M. Geodiversity: valuing and conserving abiotic nature. Chichester: Wiley, 2004.

GRAY, M., GORDON, J. E.; BROWN, E. J. Geodiversity and the ecosystem approach: the contribution of geoscience in delivering integrated environmental management. Proceedings of the Geologists' Association, 124(4), 659-673. 2013.

GUIMARÃES, G. B.; MELO, M. S.; MOCHIUTTI, N. F. Desafios da geoconservação nos Campos Gerais do Paraná. Revista do Instituto de Geociências, v. 5. São Paulo, p. 47-61, 2009.

GUIMARAES, G. B.; PONTES, H. S.; MOCHIUTTI, N. F., MASSUQUETO, L. L. KÖENE, R. Cavernas da região da serra da Pedra Branca, Tibagi (PR) e seus diferentes valores geocientíficos: possibilidade de conflitos? In: II SIMPÓSIO BRASILEIRO DE PATRIMÔNIO GEOLÓGICO E I WORKSHOP DE PATRIMÔNIO GEOLÓGICO CONSTRUÍDO, 2013, Ouro Preto (MG), 2013.

HARDT, R.; RODET, J.; PINTO, S. A. F.; WILLEMS, L. Exemplos brasileiros de carste em arenito: Chapada dos Guimarães (MT) e Serra de Itaqueri (SP). SBE - Campinas, SP. EspeleoTema. v. 20, n.1/2, p.7-23, 2009.

HARDT, R. Da carstificação em arenitos. Aproximação com o suporte de geotecnologias. 2011. Tese (Doutorado em Geografia) - Instituto de Geociências e Ciências Exatas, Universidade Estadual Paulista, Rio Claro.

HÄUSELMANN, P. UIS Mapping Grades (Technical Note). International Journal of Speleology - Informatics commission working group - Survey and mapping, 2012.

KLIMCHOUK, A. Principal features of hypogene speleogenesis. Hypogene speleogenesis and karst hydrogeology of artesian basins. Ukrainian Institute of Speleology and Karstology, Special Paper 1, p. 7-15, 2009.

LICCARDO, A.; PIERKARZ, G.; SALAMUNI, E. Geoturismo em Curitiba. Curitiba: Mineropar, 2008. 
LOPES, L. S. O.; ARAÚJO, J. L. L. Princípios e estratégias de geoconservação. Observatorium: Revista Eletrônica de Geografia, v. 3, n.7, p. 66-78, 2011.

MAACK, R. Mapa fitogeográfico do Estado do Paraná. Curitiba: Instituto de Biologia e Pesquisa Tecnológica e Instituto Nacional do Pinho, 1950.

MAACK, R. Geografia física do Estado do Paraná. 4. ed. Ponta Grossa: Editora da UEPG, 2012.

MANTESSO NETO, V.; RUCHKYS, Ú.; MANSUR, K.; SCHOBBENHAUS, C.; NASCIMENTO, M. A. L.; LICCARDO, A.; PIEKARZ, G. História e situação atual do movimento geoturismo-geoconservação no Brasil. In: CONGRESSO BRASILEIRO DE GEOLOGIA, 44, 2008, Curitiba (PR), 2008.

MASSUQUETO, L. L. O sistema cárstico do Sumidouro do Rio Quebra-Perna (Ponta Grossa - PR): caracterização da geodiversidade e de seus valores. 2010. Monografia (Graduação em Bacharelado em Geografia) - Departamento de Geociências, Universidade Estadual de Ponta Grossa.

MASSUQUETO, L. L. Estudo do manejo turístico na gruta de Pinheiro Seco (PR): estratégias para a geoconservação do patrimônio espeleológico. 2013. Dissertação (Mestrado em Gestão do Território) - Departamento de Geociências, Universidade Estadual de Ponta Grossa, Ponta Grossa.

MELO, M. S.; MENEGUZZO, I. S. Patrimônio natural dos Campos Gerais do Paraná. In: DITZEL, C. H. M.; LÖWEN SAHR, C. L. Espaço e Cultura: Ponta Grossa e os Campos Gerais. Ponta Grossa: Editora da UEPG, 2001. Cap. 23, p. 415-428.

MELO, M. S.; BURIGO, G. B.; MELEK, P. R. Formas de relevo em arenitos dos Campos Gerais, PR. In: JORNADA CIENTÍFICA DE GEOGRAFIA, 4, 2002, Ponta Grossa. Ponta Grossa (PR): Universidade Estadual de Ponta Grossa, 2002, p. 99-100.

MELO, M. S. Formas rochosas do Parque Estadual de Vila Velha. Ponta Grossa: Editora da UEPG, 2006.

MELO, M. S.; MORO, R. S.; GUIMARÃES, G. B. Os Campos Gerais do Paraná. In: MELO, Mário Sérgio de; MORO, R. S.; GUIMARÃES, G. B. Patrimônio Natural dos Campos Gerais do Paraná. Ponta Grossa: Editora UEPG, 2007. Cap. 01, p. 17-22.

MELO, M. S.; GUIMARÃES, G. B.; PONTES, H. S.; MASSUQUETO, L. L.; PIGURIM, I.; BAGATIM, H. Q.; GIANNINI, P. C. F. Carste em rochas não-carbonáticas: o exemplo dos 
arenitos da Formação Furnas, Campos Gerais do Paraná/Brasil e as suas implicações para a região. SBE-Campinas, SP. Espeleo-Tema. v. 22, n. 1, p. 81-97, 2011.

MENEGUZZO, I. S. Geoturismo no Parque Estadual do Vale do Codó, Paraná. In: MENEGUZZO, I. S. Unidades de conservação nos Campos Gerais do Paraná: diferentes abordagens. Ponta Grossa: Estúdio Texto, 2015. p. 69-84.

MINEROPAR. Folha Geológica Telêmaco Borba - 1: 250.000. Minerais do Paraná S/A. 2005.

MOCHIUTTI, N. F.; GUIMARÃES, G. B.; MELO, M. S. Os valores da geodiversidade da região de Piraí da Serra, Paraná. Geociências, v. 30, p. 651-668, 2011.

MOREIRA, J. C. Geoturismo e interpretação ambiental. Ponta Grossa: Editora da UEPG, 2011.

PENTEADO, M. M. Fundamentos de Geomorfologia. Rio de Janeiro: IBGE, 1983.

PEREIRA, R. F.; BRILHA, J.; MARTINEZ, J. E. Proposta de enquadramento da geoconservação na legislação ambiental brasileira. In: Conferência Internacional: As Geociências no Desenvolvimento das Comunidades Lusófanas, 2008, Memórias e Notícias. Coimbra: Portugal, p. 491-494. 2008.

PONTES, H. S. Caverna da Chaminé, Ponta Grossa, Paraná. Exemplo de Relevo Cárstico na Formação Furnas. 2010. Monografia (Graduação em Bacharelado em Geografia) Departamento de Geociências, Universidade Estadual de Ponta Grossa, Ponta Grossa.

PONTES, H. S.; MASSUQUETO, L. L. Geoturismo no carste da Formação Furnas: proposta de roteiro no Município de Ponta Grossa, Campos Gerais do Paraná. In: I CONGRESSO DE TURISMO DOS CAMPOS GERAIS, 2012, Ponta Grossa (PR), s/p. 2012.

PONTES, H. S. Espacialização de feições cársticas da Formação Furnas: ferramenta para gestão do território no Município de Ponta Grossa (PR). 2014. Dissertação (Mestrado em Gestão do Território) - Departamento de Geociências, Universidade Estadual de Ponta Grossa, Ponta Grossa.

PONTES, H. S., MASSUQUETO, L. L., FERNANDES, L. A., FOLTRAN, A. C., DE MELO, M. S., \& MOREIRA, J. C.. Caves Geodiversity Evaluation as an Instrument to the Management of the Campos Gerais National Park, Southern Brazil. Geoheritage, 11(2), 641-651. 2018.

SPOLADORE, A. A geologia e a geoespeleologia como instrumento de planejamento para o desenvolvimento do turismo - O caso de São Jerônimo da Serra/PR. 2006. Tese 
(Doutorado em Geociências e Meio Ambiente) - Instituto de Geociências e Ciências Exatas, Universidade Estadual Paulista, Rio Claro.

STRUGALE, M. Arcabouço e Evolução Estrutural do Arco de Ponta Grossa no Grupo São Bento (mesozoico): implicações na hidrodinâmica do Aqüífero Guarani e na migração de hidrocarbonetos na Bacia do Paraná. Boletim Paranaense de Geociências, n. 52, p. 97-114. 2003.

VIOLA, E. J. Meio ambiente, desenvolvimento e cidadania: desafios para as ciências sociais. São Paulo: Cortez, 1995.

WRAY, R. A global review of solutional weathering forms on quartz sandstones. EarthScience Reviews, n. 42, p.137-160, 1997.

WRAY, R. Phreatic drainage conduits within quartz sandstone: Evidence from the Jurassic Precipice Sandstone, Carnarvon Range, Queensland, Australia. Geomorphology 110 (3-4). p. 203-211, 2009.

ZALÁN, P. V.; WOLFF, S.; CONCEIÇÃO, J. C. J.; MARQUES, A.; ASTOLFI, M. A. M.; VIEIRA, I. S.; APPI, V. T.; ZANOTTO, O. A. Bacia do Paraná. In: GABAGLIA, G. P. R.; MILANI, E. J. Origem e evolução de Bacias Sedimentares. 2. ed. Rio de Janeiro: Gávea, 1990. p. 135-168.

Recebido em 09 de abril de 2020

Aceito em 14 de dezembro de 2020

Publicado em 07 de maio de 2021 